\title{
Clustering of lifestyle risk behaviours and its determinants among school-going adolescents in a middle-income country: a cross-sectional study
}

Chien Huey Teh ${ }^{1 *}$ D, Ming Woey Teh², Kuang Hock Lim', Chee Cheong Kee ${ }^{1}$, Mohd Ghazali Sumarni ${ }^{1}$, Pei Pei Heng ${ }^{1}$, Tajul Hassan Mohd Zahari ${ }^{1}$, Ying Ying Chan ${ }^{3}$, Md Iderus Nuur Hafiza ${ }^{1}$, Eng Ong Tee ${ }^{4}$ and Kamaludin Fadzilah ${ }^{1}$

\begin{abstract}
Background: Lifestyle risk behaviours such as smoking, alcohol consumption, physical inactivity, sedentary behaviour and low fruit/vegetable intake have been identified as the major causes of chronic diseases. Such behaviours are usually instigated in adolescence and tend to persist into adulthood. Studies on the clustering of lifestyle risk behaviours among adolescents are scarce, particularly in developing countries. Therefore, the present paper aimed to determine the clustering of lifestyle risk behaviours and its determinants among school-going adolescents in Malaysia.

Methods: Data were extracted from a cross-sectional study, the Malaysian Adolescent Health Risk Behaviour (MyAHRB) study, which was conducted from May to September 2013 across 11 states in Peninsular Malaysia. A two-stage proportionate-to-size sampling method was employed to select a total of 3578 school-going adolescents aged 16-17 years from 20 selected schools in urban and rural settlements, respectively. The MyAHRB study adopted a set of self-administered questionnaires adapted from the Global School-based Student's Health Survey (GSHS) and the Youth Risk Behaviour Surveillance.

Results: The results from the analysis of 2991 school-going adolescents aged 16-17 years showed that 16 (in boys) and 15 (in girls) out of 32 combinations of lifestyle risk behaviours clustered. Girls (aOR 2.82, 95\% Cl: 2.32-3.43) were significantly more likely to have clustered risk behaviours than boys; however, no significant associated factors were observed among girls. In contrast, boys of Malay descent (aOR 0.64, 95\% Cl: 0.46-0.89) or boys who had at least three friends (aOR 0.65, 95\% Cl: 0.43-0.99) were less likely to engage in multiple risk behaviours.
\end{abstract}

Conclusion: The present study demonstrated the clustering of multiple risk behaviours that occurred in both genders; these results suggest that multiple behaviour intervention programmes, instead of programmes based on siloed approaches, should be advocated and targeted to the high-risk sub-populations identified in the present study.

Keywords: Clustering, Multiple health risk behaviours, Risk factors, School-going adolescents, MyAHRB

\footnotetext{
* Correspondence: chienhuey@imr.gov.my

${ }^{1}$ Institute for Medical Research, Ministry of Health, Jalan Setia Murni U13/52,

40170 Seksyen U13, Bandar Setia Alam, Malaysia

Full list of author information is available at the end of the article
}

(c) The Author(s). 2019 Open Access This article is distributed under the terms of the Creative Commons Attribution 4.0 International License (http://creativecommons.org/licenses/by/4.0/), which permits unrestricted use, distribution, and reproduction in any medium, provided you give appropriate credit to the original author(s) and the source, provide a link to the Creative Commons license, and indicate if changes were made. The Creative Commons Public Domain Dedication waiver (http://creativecommons.org/publicdomain/zero/1.0/) applies to the data made available in this article, unless otherwise stated. 


\section{Background}

Adolescence is one of the critical transitions in human growth during which young adults undergo tremendous physiological and psychological developments to transition into adulthood [1]. Previous studies have demonstrated that adolescents tend to engage in a spectrum of lifestyle risk behaviours, such as smoking, drinking alcohol, being physically inactive, engaging in sedentary behaviour and having low fruit/vegetable intake [2, 3]; these unhealthy behaviours are more likely to continue into adulthood [4]. Therefore, due attention should be given to these preventable and modifiable lifestyle risk behaviours in view of their well-known contributions to the global burden of noncommunicable diseases such as cardiovascular disease, some cancers, chronic respiratory disease and diabetes [5], particularly among adolescents.

In view of this, there have been extensive international and local studies on the magnitude and determinants of individual lifestyle risk behaviours among adolescents, such as smoking [6, 7], alcohol consumption [8, 9], physical inactivity $[10,11]$, sedentary behaviour $[12,13]$ and low fruit/vegetable intake $[14,15]$. However, when these risk behaviours clustered more than expected by the independent occurrence of an individual risk behaviour, a clustered effect is observed [16]. Clustering lifestyle risk behaviours have a profound negative impact on overall health compared to the effect of individual risk behaviours since previous studies have demonstrated the synergistic rather than additive effects of risk behaviours on health, particularly on the increased risk for cardiovascular diseases [17, 18] and cancer [19, 20]. According to Jessor's problem-behaviour theory, adolescents tend to be involved in more than one problem behaviour due to shared linkages of such behaviours in the social ecology of adolescence [21]. This clustering of risk behaviours is distinct from the co-occurrence of multiple risk behaviours, as the former occurs due to an underlying association between the co-occurring risk behaviours, while the latter merely describes the concurrent but independent engagement in multiple risk behaviours [22].

A number of studies have examined the prevalence of multiple co-occurring risk behaviours and their associated factors [3]. For instance, a study in San Diego in the United States reported that approximately $80 \%$ of adolescents aged 11 to 15 years had multiple risk behaviours (physical inactivity, sedentary behaviour, low fruit/vegetable intake, fat consumption) [23]. Dumith and colleagues also reported that $93.5 \%$ of Brazilian adolescents had cooccurrences of more than two risk behaviours (smoking, alcohol use, low fruit intake and/or physical inactivity), and adolescents who were female, were black or had a lower socioeconomic level were found to be more likely to have simultaneous occurrences of at least 3 risk behaviours than their corresponding counterparts [24].
Nonetheless, cross-sectional and cohort studies that demonstrate the magnitude and associated factors of clustered lifestyle risk behaviours among adolescents are scarce [3]. Previous observational studies that demonstrated the significant clustering effect of risk behaviours (smoking, alcohol consumption, physical inactivity, low fruit/vegetable intake) between men and women were conducted with adults $[25,26]$. A systematic review conducted by Leech and colleagues in 2014 demonstrated that only eight studies have investigated the clustering of physical inactivity, sedentary behaviour and diet among children and adolescents, and these studies revealed that female, older age and lower socio-economic status were significant predictors for clustering of physical inactivity, sedentary behaviour and diet [2].

To the best of our knowledge, no study has attempted to explore the clustering of lifestyle risk behaviours and its associated factors among Malaysian adolescents. Therefore, the present paper aimed to determine the clustering pattern of five lifestyle risk behaviours (smoking, alcohol consumption, physical inactivity, sedentary behaviour and low fruit/vegetable intake) and investigate their associations with socio-demographic factors (gender, ethnicity, parental occupation, parental educational level, parental marital status, academic performance, and number of close friends) among school-going adolescents in Malaysia in order to identify high-risk sub-populations and hence could potentially guide the implementation of health promotion, education and interventional programmes pertaining to these lifestyle risk behaviours.

\section{Methods}

\section{Study design}

Data were extracted from the cross-sectional Malaysian Adolescent Health Risk Behaviour (MyAHRB) study, which was conducted from May to September 2013 across 11 states in Peninsular Malaysia. The sampling of schools was performed via a two-stage proportionate-tosize sampling method in order to ensure the representativeness of the findings. The first-stage stratification involved the selection of districts, and the second-stage stratification was performed by locality (urban/rural). An urban area was defined as a gazetted area with adjoining built-up areas of more than 10,000 people; otherwise, the area was categorised as a rural area. A total of 20 districts were selected from the 11 states, and subsequently, one secondary school per locality was selected from each of these districts via a simple random sampling method. All students who were 16-17 years old and had Malaysian citizenship from the 20 selected schools in urban areas and 20 selected schools in rural areas were recruited into the MyAHRB study. A design effect of 3 was used to adjust for the clustering effect within schools and districts. As a result, an optimum 
number of 3578 school-going adolescents aged 16-17 years were enrolled in the study. A detailed calculation of the optimum sample size of 3578 for the MyAHRB study was described elsewhere [7].

\section{Study instruments}

The MyAHRB study employed a set of self-administered questionnaires adopted from the Global School-based Student's Health Survey (GSHS) [27] and the Youth Risk Behaviour Surveillance [28] and adapted to the local socio-cultural context. The MyAHRB questionnaire was translated and back translated by a panel of language and content experts into our national language, Bahasa Malaysia, to establish content validity. The questionnaire was also pre-tested in selected schools in the state of Kuala Lumpur in a pilot study to establish face validity.

This validated self-administered questionnaire has two components: socio-demographics (age, gender, ethnicity, parental occupation, parental education level, parental marital status, family size, and self-perceived academic performance) and health behaviours (alcohol use, dietary behaviour, self-perceived body mass index (BMI) status, illicit drug use, mental health, physical inactivity, unsafe sexual behaviours, tobacco use, violence and unintentional injuries, and road safety).

\section{Data collection}

Prior to data collection at the selected schools, written passive consent was obtained from the parents/guardians of the selected students with the assistance of the school administrators. Parents/guardians who did not allow their children to participate in the MyAHRB study were asked to return the consent forms, and these students did not participate in this study. During the data collection day, only students with passive consent were recruited into the study and briefed on the self-administered questionnaire by properly trained research team members. No teachers were allowed to be present during the questionnaire-answering session. All completed anonymous questionnaires were sealed in envelopes to ensure the confidentiality of the data.

\section{Smoking}

Current smoking status was measured by a closed question, "In the last 30 days, on how many days have you smoked?". Respondents who answered " 1 to 2 days", "3 to 5 days", "6 to 9 days", "10 to 19 days", "20 to 29 days" or "every day" to the item were categorised as current smokers, whilst respondents who answered "no" were categorised as non-smokers.

\section{Alcohol consumption}

Current drinking behaviour was assessed by a closed question, "In the last 30 days, on how many days have you had at least one alcoholic beverage?". Respondents who answered " 1 to 2 days", " 3 to 5 days", "6 to 9 days", "10 to 19 days", "20 to 29 days" or "every day" to the item were categorised as current drinkers, whilst respondents who answered "no" were categorised as non-drinkers.

\section{Physical inactivity}

Respondents who reported "0 days" to the item "During the past 7 days, on how many days were you physically active for a total of at least 60 minutes per day?" were considered inactive, and those who reported at least 1 day of engagement in at least $60 \mathrm{~min}$ of physical activity were considered physically active [29].

\section{Sedentary behaviour}

Respondents who answered "3-4 h/day", "5-6 h/day", "7$8 \mathrm{~h} /$ day" or "more than 8 hours/day" to the item "How much time do you spend during a typical or usual day sitting and watching television, playing computer games, talking with friends, or doing other sitting activities?" were categorised as sedentary; whilst those answered " $1-2 \mathrm{~h} /$ day" or "less than 1 hour/day" were classified as not being sedentary [30].

\section{Low fruit/vegetable intake}

Two items were used to assess the level of fruit and vegetable intake, namely, "In the last 30 days, how many times per day have you eaten fruits?" and "In the last 30 days, how times per day have you eaten vegetables?". In the present study, the number of times the respondents ate a fruit/vegetable was considered as the proxy for the number of servings of fruits/vegetables consumed. Therefore, respondents who had eaten fruits and/or vegetables at least 5 times per day were considered to have adequate intake of fruit and vegetables, whilst respondents who failed to do so were considered to be consuming an inadequate amount of fruit and vegetable [31].

\section{Data analysis}

Descriptive analyses by gender were employed to depict the socio-demographic profile and individual prevalence of smoking, alcohol consumption, physical inactivity, sedentary behaviour and low fruit/vegetable intake as well as the total risk score of the recruited respondents. All five risk behaviours were dichotomised (presence of risk behaviour $=1$; absence of risk behaviour $=0$ ), and thus, each respondent was assigned a total risk score ranging from 0 to 5 . For instance, respondents who had none of the five risk behaviours had a risk score of 0 , while respondents with all five risk behaviours had a score of 5 .

The clustering of lifestyle risk behaviours (smoking, alcohol consumption, physical inactivity, sedentary behaviour and low fruit/vegetable intake) were determined 
via the ratio of observed-to-expected prevalence $(\mathrm{O} / \mathrm{E})$. Clustering occurred when the observed prevalence $(\mathrm{O})$ of a particular combination of lifestyle risk behaviours exceeded the expected prevalence of the combination (E) based on the random occurrence of the corresponding risk behaviours, which is when the $\mathrm{O} / \mathrm{E}$ ratio is more than 1.0 [16].

Subsequently, in order to elucidate the associated factors for clustered risk behaviours (combinations of risk behaviours that had an $\mathrm{O} / \mathrm{E}$ ratio of more than 1.0), multivariable binary logistic regressions were performed. The dependent variable, clustering of risk behaviours, was computed as follows: individuals with combinations of risk behaviours that had an O/E ratio of more than 1.0 (clustered risk behaviours) were coded as " 1 ", while those with combinations of risk behaviours that had an $\mathrm{O} / \mathrm{E}$ ratio of less than 1.0 were coded as "0". Independent variables such as ethnicity (Malay, non-Malay), parental education level (no formal education, primary school, secondary school, tertiary education), parents' occupation (management and clerical, manual workers, not working), parents' marital status (married, divorced), self-perceived academic performance (good, fair or poor) and number of close friends (fewer than three, at least three) were included simultaneously in the binary logistic regression model in order to obtain adjusted odd ratios (ORs). These analyses were performed by gender since there were significant interactions between gender, parental educational level and occupation. Hosmer-Lemeshow values of 0.701 (overall), 0.920 (for boys) and 0.739 (for girls) indicated that the data fit the binary logistic regression models well. All statistical analyses were performed at a 95\% confidence interval using SPSS statistical software version 20 (IBM Corp., Armonk, NY, USA).

\section{Results}

Of the 3578 eligible respondents, $83.6 \%(n=2991)$ participated in the MyAHRB study. Among the participated respondents, $84.9 \%(n=2538)$ of them provided a complete response to all five lifestyle risk behaviours of concern, whilst those with incomplete responses were excluded from the present study $(n=453)$. Further analyses of socio-demographic profiles between the study sample and those with incomplete information for the five lifestyle risk behaviours revealed nonsignificant differences (data not shown) and hence precluded non-response bias. As depicted in Table 1, approximately nine in ten adolescents were physically inactive (85.5\%), seven in ten reported low intake of fruit/vegetable (70.4\%), more than half were sedentary (56.0\%), 14.6\% smoked, and 5.0\% reported alcohol consumption. For the total number of risk factors, $2.0 \%$ of the adolescents did not have any lifestyle risk behaviours, $14.9 \%$ had only one risk behaviour, and $0.6 \%$ had all five risk behaviours. More than one-third of the adolescents had simultaneous occurrence of $2(39.7 \%)$ or $3(37.1 \%)$ risk behaviours, while $5.8 \%$ had four risk behaviours that occurred simultaneously.

As demonstrated in Table 2, the clustering effect, which is when the observed prevalence of a particular combination of risk behaviours was higher than the expected prevalence based on the random occurrence of the individual risk behaviours, was detected in 16 and 15 out of 32 different combinations of lifestyle risk behaviours in boys and girls, respectively. Generally, the O/E ratios were higher in girls than in boys. Among the girls, the clustering of all five risk behaviours was strongest across the 32 combinations with an $\mathrm{O} / \mathrm{E}$ ratio of 13.53 . The highest $\mathrm{O} / \mathrm{E}$ ratio observed in boys was 4.38 , where smoking, alcohol consumption and sedentary behaviour were clustered. It was notable that the clustering of smoking and alcohol use together with any of the other three risk behaviours was observed in both genders. Specifically, the clustering of smoking, alcohol consumption and sedentary behaviour $(\mathrm{O} / \mathrm{E}$ ratio $=4.38)$, and smoking, alcohol consumption, sedentary behaviour and low fruit/ vegetable intake $(\mathrm{O} / \mathrm{E}$ ratio $=1.72)$ were strongest in boys. On the other hand, the clustering of smoking, alcohol consumption and physical inactivity $(\mathrm{O} / \mathrm{E}$ ratio $=$ 7.50), and smoking, alcohol consumption, physical inactivity and sedentary $(\mathrm{O} / \mathrm{E}$ ratio $=10.92)$ were strongest in girls. In addition, it was noteworthy that the individual prevalence of low fruit/vegetable intake was less prevalent than the expected level $(\mathrm{O} / \mathrm{E}$ ratio $=1.0$ in boys and 0.68 in girls); however, when it co-occurred with smoking, alcohol use and physical inactivity, the observed prevalence was $38 \%$ greater in boys $(\mathrm{O} / \mathrm{E}$ ratio $=$ $1.38)$ and $210 \%$ greater in girls $(\mathrm{O} / \mathrm{E}$ ratio $=3.10)$ than the expected prevalence that the four risk behaviours occurred randomly in the study population.

Girls (aOR 2.82, 95\% CI: 2.32-3.43) were found to be significantly more likely to have clustered lifestyle health risk behaviours than boys after we controlled for sociodemographic factors (data not shown). However, no significant determinants of the clustering of risk behaviours were observed among girls (Table 3). On the other hand, boys who were of Malay descent (aOR 0.64, 95\% CI: 0.46-0.89; non-Malay as the reference group) or who had at least three friends (aOR 0.65, 95\% CI: 0.43-0.99; fewer than three friends as the reference group) were less likely to engage in clusters of lifestyle risk behaviours (Table 3).

\section{Discussion}

This is the first study to investigate the clustering pattern of five major lifestyle risk behaviours (smoking, partake of alcohol, physical inactivity, sedentary behavior and inadequate fruit or vegetable intake) of chronic noncommunicable diseases [32] and its determinants among school-going adolescents aged $16-17$ years in the multi- 
Table 1 Socio-demographics and lifestyle risk behaviour profile of 2538 school-going adolescents in Peninsular Malaysia, MyAHRB 2013

\begin{tabular}{|c|c|c|c|c|c|c|}
\hline \multirow[t]{3}{*}{ Variable } & \multicolumn{2}{|l|}{ All } & \multicolumn{2}{|l|}{ Boys } & \multicolumn{2}{|l|}{ Girls } \\
\hline & $\bar{n}$ & $\%$ & $\bar{n}$ & $\%$ & $\bar{n}$ & $\%$ \\
\hline & \multicolumn{2}{|l|}{2538} & 1214 & 47.8 & 1324 & 52.2 \\
\hline \multicolumn{7}{|l|}{ Ethnicity } \\
\hline Malay & 2014 & 79.4 & 943 & 77.7 & 1071 & 80.9 \\
\hline Non-Malay & 524 & 20.6 & 271 & 22.3 & 253 & 19.1 \\
\hline \multicolumn{7}{|l|}{ Father's Occupation } \\
\hline Management and clerical & 504 & 22.2 & 222 & 20.6 & 282 & 23.7 \\
\hline Manual workers & 1670 & 73.7 & 807 & 74.9 & 863 & 72.5 \\
\hline Not working & 93 & 4.1 & 48 & 4.5 & 45 & 3.8 \\
\hline \multicolumn{7}{|l|}{ Mother's Occupation } \\
\hline Management and clerical & 501 & 21.6 & 212 & 19.5 & 289 & 23.5 \\
\hline Manual workers & 294 & 12.7 & 143 & 13.2 & 151 & 12.3 \\
\hline Not working & 1520 & 65.7 & 732 & 67.3 & 788 & 64.2 \\
\hline \multicolumn{7}{|l|}{ Father's Education Level } \\
\hline No formal education & 52 & 2.1 & 22 & 1.9 & 30 & 2.3 \\
\hline Primary & 215 & 8.7 & 84 & 7.1 & 131 & 10.2 \\
\hline Secondary & 1464 & 59.4 & 717 & 61.0 & 747 & 58.0 \\
\hline Tertiary & 733 & 29.7 & 352 & 30.0 & 381 & 29.6 \\
\hline \multicolumn{7}{|l|}{ Mother's Education Level } \\
\hline No formal education & 55 & 2.2 & 31 & 2.6 & 24 & 1.9 \\
\hline Primary & 224 & 9.1 & 102 & 8.7 & 122 & 9.4 \\
\hline Secondary & 1609 & 65.0 & 780 & 66.2 & 829 & 64.0 \\
\hline Tertiary & 586 & 23.7 & 266 & 22.6 & 320 & 24.7 \\
\hline \multicolumn{7}{|l|}{ Parents' Marital Status } \\
\hline Married & 2377 & 94.6 & 1137 & 94.5 & 1240 & 94.6 \\
\hline Divorced & 137 & 5.4 & 66 & 5.5 & 71 & 5.4 \\
\hline \multicolumn{7}{|l|}{ Academic Performance } \\
\hline Poor/Fair & 972 & 38.5 & 538 & 44.4 & 434 & 33.0 \\
\hline Good & 1555 & 61.5 & 674 & 55.6 & 881 & 67.0 \\
\hline \multicolumn{7}{|l|}{ Number of Close Friend } \\
\hline Fewer than 3 & 370 & 14.6 & 145 & 12.0 & 225 & 17.1 \\
\hline At least 3 & 2158 & 85.4 & 1064 & 88.0 & 1094 & 82.9 \\
\hline \multicolumn{7}{|l|}{ Lifestyle Risk Behaviour } \\
\hline Smoking & 371 & 14.6 & 337 & 27.8 & 34 & 2.6 \\
\hline Alcohol use & 127 & 5.0 & 80 & 6.6 & 47 & 3.5 \\
\hline Physical inactivity & 2171 & 85.5 & 983 & 81.0 & 1188 & 89.7 \\
\hline Sedentary behaviour & 1422 & 56.0 & 656 & 54.0 & 766 & 57.9 \\
\hline Low food/vegetable intake & 1787 & 70.4 & 850 & 70.0 & 937 & 70.8 \\
\hline \multicolumn{7}{|l|}{ Number of Risk Factor/Risk Score } \\
\hline 0 & 50 & 2.0 & 28 & 2.3 & 22 & 1.7 \\
\hline 1 & 378 & 14.9 & 179 & 14.7 & 199 & 15.0 \\
\hline 2 & 1007 & 39.7 & 434 & 35.7 & 573 & 43.3 \\
\hline 3 & 941 & 37.1 & 442 & 36.4 & 499 & 37.7 \\
\hline
\end{tabular}

Table 1 Socio-demographics and lifestyle risk behaviour profile of 2538 school-going adolescents in Peninsular Malaysia, MyAHRB 2013 (Continued)

\begin{tabular}{|c|c|c|c|c|c|c|}
\hline \multirow[t]{3}{*}{ Variable } & \multicolumn{2}{|l|}{ All } & \multicolumn{2}{|l|}{ Boys } & \multicolumn{2}{|l|}{ Girls } \\
\hline & $\mathrm{n}$ & $\%$ & $\bar{n}$ & $\%$ & $\mathrm{n}$ & $\%$ \\
\hline & 253 & & 1214 & 47.8 & 1324 & 52.2 \\
\hline 4 & 147 & 5.8 & 122 & 10.0 & 25 & 1.9 \\
\hline 5 & 15 & 0.6 & 9 & 0.7 & 6 & 0.5 \\
\hline
\end{tabular}

ethnicity country of Malaysia with diverse socio-demographics and cultural backgrounds.

Generally, two major approaches are commonly used by researchers to analyse multiple risk behaviours, namely, analysis of co-occurrence of two or more risk behaviours and analysis of clustering of co-occurring risk behaviours. However, the analysis of co-occurrence, which merely examines the prevalence of different combinations of risk behaviours and/or the prevalence of the sum of risk scores, cannot demonstrate the underlying association between the co-occurring behaviours as the analysis of clustering can. The analysis of clustering, on the other hand, can be performed via two approaches: the first is via the computation of the observed prevalence-to-expected prevalence $(\mathrm{O} / \mathrm{E})$ ratio, and the second is via statistical methods such as factor analysis, latent class analysis and cluster analysis. Nonetheless, the cluster analyses are subjected to disputable issues about how clusters are defined and operationalised [22]. Since this study is the first of its kind in Malaysia, the $\mathrm{O} / \mathrm{E}$ ratio method that is able to illustrate the detailed clustering effect of all possible combinations of the five risk behaviours of concern were chosen.

Previous studies have demonstrated the clustering of health risk behaviours among adolescents via the $\mathrm{O} / \mathrm{E}$ ratio method. However, comparisons of findings between the present study and previous similar studies have to be performed with caution due to the variations in investigating different risk factors and defining terms and cut-off points for the dichotomisation of risk factors as well as differing age groups and targeted populations of recruited adolescents [23, 24, 33, 34]. Compared with the study conducted by Dumith and colleagues [24], who employed the same definitions for smoking, alcohol consumption and physical inactivity among 3990 adolescents who were 14-15 years old from the 1993 Pelotas birth cohort in a medium-sized city in Southern Brazil, the present findings demonstrated that Malaysian adolescents had a lower prevalence of alcohol use $(5.0 \%$ in the present study vs $24.8 \%$ ) but a higher prevalence of smoking (14.6\% in the present study vs $5.7 \%$ ) and higher rates of physical inactivity $(85.5 \%$ in the present study vs 70.4\%). Nonetheless, in contrast to Brazilian adolescents, the prevalence of smoking and alcohol use were lower 
Table 2 Clustering of lifestyle risk behaviours among school-going adolescents in Peninsular Malaysia by gender, MyAHRB 2013

\begin{tabular}{|c|c|c|c|c|c|c|c|c|c|c|c|}
\hline $\begin{array}{l}\text { Number of risk } \\
\text { factors }\end{array}$ & Smoking & $\begin{array}{l}\text { Alcohol } \\
\text { use }\end{array}$ & $\begin{array}{l}\text { Physically } \\
\text { inactive }\end{array}$ & $\begin{array}{l}\text { Sedentary } \\
\text { behaviour }\end{array}$ & $\begin{array}{l}\text { Low fruit/vegetable } \\
\text { intake }\end{array}$ & Boys & & & Girls & & \\
\hline & & & & & & $\begin{array}{l}0 \\
(\%)\end{array}$ & $\begin{array}{l}\mathrm{E} \\
(\%)\end{array}$ & O/E & $\begin{array}{l}0 \\
(\%)\end{array}$ & $\begin{array}{l}\mathrm{E} \\
(\%)\end{array}$ & O/E \\
\hline 0 & - & - & - & - & - & 2.31 & 1.77 & 1.30 & 1.66 & 1.19 & 1.40 \\
\hline \multirow[t]{5}{*}{1} & + & - & - & - & - & 0.99 & 0.68 & 1.45 & 0.00 & 0.03 & 0.00 \\
\hline & - & + & - & - & - & 0.16 & 0.12 & 1.32 & 0.15 & 0.04 & 3.45 \\
\hline & - & - & + & - & - & 7.25 & 7.53 & 0.96 & 10.95 & 10.39 & 1.05 \\
\hline & - & - & - & + & - & 2.22 & 2.08 & 1.07 & 1.96 & 1.63 & 1.20 \\
\hline & - & - & - & - & + & 4.12 & 4.13 & 1.00 & 1.96 & 2.88 & 0.68 \\
\hline \multirow[t]{10}{*}{2} & + & + & - & - & - & 0.08 & 0.05 & 1.72 & 0.00 & 0.00 & - \\
\hline & + & - & + & - & - & 3.21 & 2.89 & 1.11 & 0.23 & 0.27 & 0.83 \\
\hline & + & - & - & + & - & 1.15 & 0.80 & 1.44 & 0.00 & 0.04 & 0.00 \\
\hline & + & - & - & - & + & 1.57 & 1.59 & 0.99 & 0.00 & 0.08 & 0.00 \\
\hline & - & + & + & - & - & 0.49 & 0.53 & 0.93 & 0.15 & 0.38 & 0.40 \\
\hline & - & + & - & + & - & 0.16 & 0.15 & 1.12 & 0.15 & 0.06 & 2.51 \\
\hline & - & + & - & - & + & 0.08 & 0.29 & 0.28 & 0.15 & 0.11 & 1.43 \\
\hline & - & - & + & + & - & 7.33 & 8.85 & 0.83 & 12.99 & 14.26 & 0.91 \\
\hline & - & - & + & - & + & 18.04 & 17.58 & 1.03 & 25.76 & 25.15 & 1.02 \\
\hline & - & - & - & + & + & 3.62 & 4.86 & 0.75 & 3.85 & 3.95 & 0.97 \\
\hline \multirow[t]{10}{*}{3} & + & + & + & - & - & 0.08 & 0.20 & 0.40 & 0.08 & 0.01 & 7.50 \\
\hline & + & + & - & + & - & 0.25 & 0.06 & 4.38 & 0.00 & 0.00 & - \\
\hline & + & + & - & - & + & 0.00 & 0.11 & 0.00 & 0.00 & 0.00 & - \\
\hline & + & - & + & + & - & 3.21 & 3.40 & 0.94 & 0.45 & 0.38 & 1.21 \\
\hline & + & - & + & - & + & 6.01 & 6.76 & 0.89 & 0.38 & 0.66 & 0.57 \\
\hline & + & - & - & + & + & 1.65 & 1.87 & 0.88 & 0.15 & 0.10 & 1.45 \\
\hline & - & + & + & + & - & 0.82 & 0.62 & 1.32 & 0.30 & 0.52 & 0.58 \\
\hline & - & + & + & - & + & 0.91 & 1.24 & 0.73 & 0.60 & 0.93 & 0.65 \\
\hline & - & - & + & + & + & 23.15 & 20.67 & 1.12 & 35.50 & 34.52 & 1.03 \\
\hline & - & + & - & + & + & 0.33 & 0.34 & 0.96 & 0.23 & 0.15 & 1.56 \\
\hline \multirow[t]{5}{*}{4} & + & + & + & + & - & 0.25 & 0.24 & 1.03 & 0.15 & 0.01 & 10.92 \\
\hline & - & + & + & + & + & 1.24 & 1.46 & 0.85 & 1.06 & 1.27 & 0.83 \\
\hline & + & - & + & + & + & 7.58 & 7.94 & 0.95 & 0.60 & 0.91 & 0.66 \\
\hline & + & + & - & + & + & 0.33 & 0.13 & 2.50 & 0.00 & 0.00 & - \\
\hline & + & + & + & - & + & 0.66 & 0.48 & 1.38 & 0.08 & 0.02 & 3.10 \\
\hline 5 & + & + & + & + & + & 0.74 & 0.56 & 1.32 & 0.45 & 0.03 & 13.53 \\
\hline
\end{tabular}

Values in boldface indicate presence of clustering effect

among Malaysian girls than boys. The disparity in the prevalence of smoking and alcohol use by gender that has been reported across countries [35, 36] could possibly be attributable to the differences in social norms and cultural context. This is because the social norms of smoking and alcohol use among females are generally not acceptable by Malaysian societies, and therefore, these beliefs prevent girls from engaging in such risk behaviours [7, 37].
Regarding the prevalence of multiple lifestyle risk behaviours, the prevalence of simultaneous occurrences of at least 2 risk behaviours (80\%) among Malaysian adolescents was higher than that reported among Brazilian adolescents [24], Canadian adolescents [34] and English and Brazilian adult populations [38]. On the other hand, the present findings were consistent with previous studies among Australian adolescents [33] as well as Dutch [16] and Swiss [39] adults such that a similar prevalence of 
Table 3 Adjusted odds ratios (aORs) of the clustering of health risk behaviours among school-going adolescents in Peninsular Malaysia, MyAHRB 2013

\begin{tabular}{|c|c|c|c|c|c|c|}
\hline \multirow[t]{3}{*}{ Variable } & \multicolumn{3}{|l|}{ Boys } & \multicolumn{3}{|l|}{ Girls } \\
\hline & \multirow[t]{2}{*}{ Adjusted OR } & \multicolumn{2}{|l|}{$95 \% \mathrm{Cl}$} & \multirow[t]{2}{*}{ Adjusted OR } & \multicolumn{2}{|l|}{$95 \% \mathrm{Cl}$} \\
\hline & & Lower & Upper & & Lower & Upper \\
\hline \multicolumn{7}{|l|}{ Ethnicity } \\
\hline Malay & $* 0.64$ & 0.6 & 0.89 & 0.66 & 0.432 & 1.00 \\
\hline Non-Malay & Ref & & & Ref & & \\
\hline \multicolumn{7}{|l|}{ Father's Occupation } \\
\hline Management and clerical & 1.20 & 0.61 & 2.39 & 0.50 & 0.19 & 1.28 \\
\hline Manual workers & 0.95 & 0.51 & 1.77 & 0.58 & 0.24 & 1.42 \\
\hline Not working & Ref & & & Ref & & \\
\hline \multicolumn{7}{|l|}{ Mother's Occupation } \\
\hline Management and clerical & 1.06 & 0.72 & 1.58 & 1.05 & 0.67 & 1.63 \\
\hline Manual workers & 0.98 & 0.64 & 1.49 & 0.91 & 0.56 & 1.47 \\
\hline Not working & Ref & & & Ref & & \\
\hline \multicolumn{7}{|l|}{ Father's Education Level } \\
\hline No formal education & Ref & & & Ref & & \\
\hline Primary & 1.52 & 0.41 & 5.65 & 1.78 & 0.53 & 5.97 \\
\hline Secondary & 2.14 & 0.62 & 7.43 & 1.32 & 0.43 & 4.20 \\
\hline Tertiary & 2.09 & 0.58 & 7.48 & 1.36 & 0.40 & 4.62 \\
\hline \multicolumn{7}{|l|}{ Mother's Education Level } \\
\hline No formal education & Ref & & & Ref & & \\
\hline Primary & 0.56 & 0.18 & 1.73 & 0.38 & 0.10 & 1.47 \\
\hline Secondary & 0.60 & 0.21 & 1.75 & 0.74 & 0.20 & 2.78 \\
\hline Tertiary & 0.56 & 0.18 & 1.74 & 0.61 & 0.15 & 2.49 \\
\hline \multicolumn{7}{|l|}{ Marital Status } \\
\hline Married & 1.05 & 0.56 & 1.97 & 1.18 & 0.58 & 2.40 \\
\hline Divorced & Ref & & & Ref & & \\
\hline \multicolumn{7}{|l|}{ Academic Performance } \\
\hline Poor/Fair & Ref & & & Ref & & \\
\hline Good & 1.03 & 0.79 & 1.4 & 0.85 & 0.61 & 1.17 \\
\hline \multicolumn{7}{|l|}{ Close friends } \\
\hline Fewer than 3 & Ref & & & Ref & & \\
\hline At least 3 & $* 0.65$ & 0.43 & 0.99 & 0.95 & 0.64 & 1.43 \\
\hline
\end{tabular}

*Significant values at $95 \%$ confidence interval

multiple risk behaviours was observed in both genders. These findings suggest that intervention programmes using a multiple-behaviour approach instead of a siloed approach should be advocated among adolescents, regardless of gender, in view of the rather high prevalence of multiple lifestyle risk behaviours.

In contrast to previous works that investigated only the prevalence of co-occurring risk behaviours $[23,40]$ but not clustering effects, the present study demonstrated that significant clustering of lifestyle risk behaviours was observed in 16 and 15 out of 32 different combinations of the five lifestyle risk behaviours of concern in boys and girls, respectively. The clustering of multiple risk behaviours demonstrated in the present study substantiated the findings from previous studies involving both adolescents $[24,33,34]$ and adults $[25,26,41]$. Furthermore, in concordance with previous literature, smoking and alcohol consumption were prone to cluster either alone or together with other risk behaviours in both genders $[25,34,39,41,42]$. The clustering of risk behaviours observed in the present study follows Jessor's problem-behaviour theory that adolescents who are engaged in one problem behaviour tend to also be involved in other problem behaviours due to the shared linkages of such 
behaviours in the social ecology of adolescence [21]. This suggests that joint interventions on risk behaviours that have been demonstrated to be more efficient and effective [43] should be preferred over individual behaviour interventions in order to combat the synergistic effect of clustered risk behaviours on the well-being of adolescents.

In general, more profound clustering effects of lifestyle risk behaviours were observed in girls than in boys, and such findings corroborated previous findings $[25,26]$. In the present study, although a higher observed prevalence $(\mathrm{O}$, the numerator in $\mathrm{O} / \mathrm{E}$ ratio) was found in most combinations of lifestyle risk behaviour among boys than among girls, the lower observed prevalence of individual risk behaviours in girls had given rise to a lower expected prevalence (E, the denominator in $\mathrm{O} / \mathrm{E}$ ratio) for a particular combination of risk behaviours, which subsequently increased the $\mathrm{O} / \mathrm{E}$ ratios. Therefore, more profound clustering effects of lifestyle risk behaviours were observed among the girls. In addition, another plausible reason is that although girls are generally known to have lower risk-taking behaviour (as shown by their lower prevalence of individual behaviours in the present study, except for physical inactivity), a study demonstrated that female adolescents who engaged in high-risk behaviour tend to be more involved in other high-risk behaviours than their male counterparts [44]. Furthermore, a higher level of perceived stress [45], tendency to ruminate and feelings of helplessness [46] among girls could predispose them to engage in dysfunctional coping measures such as risk behaviours to deal with stress [47]. Despite the observation of marked clustering of risk behaviours (higher O/E ratios) among girls in both the present study and previous literature, multivariable logistic analyses demonstrated that the likelihood of engaging in clusters of risk behaviours was independent of socio-demographic factors among girls. Previous studies have noted that adolescent girls were more likely to be influenced by psychosocial factors [45, 46] and therefore more likely to engage in unhealthy risk behaviours [47]. As such, in-depth investigations into the actual causal factors in future studies, particularly from the psychosocial perspective, could probably shed some light on the significant determinants of the clustering of lifestyle risk behaviours among Malaysian girls.

In contrast, being Malay or having at least 3 close friends was protective against engagement in clusters of risk behaviours in boys. As posited by social control theory [48], one of the plausible reasons for Malay (which is synonym to Muslim in Malaysia) boys being less prone to engage in clusters of lifestyle risk behaviours could be their strong proscriptive norm against consumption of alcoholic drinks [49], as compared to other ethnic counterparts in Malaysia. On the other hand, social relationships, which can be measured by the number of friends, are an important element in school connectedness [50]. School connectedness is an essential protective factor against a number of risk behaviours among adolescents because adolescents with good school connectedness believe that they are cared for by adults and peers as an individual [51] and are emotionally well [50], thereby reducing their likelihood of engaging in unhealthy behaviours. As such, the present findings corroborated the above speculation that boys with at least 3 close friends were less likely to engage in clusters of lifestyle risk behaviours than their counterparts who had fewer than 3 close friends. However, the negative association between the number of close friends and engagement in multiple risk behaviours should be further scrutinised since the health risk behaviours and other contextual factors of the respondents' close friends were not investigated in the present study. In terms of family influence, the nonsignificant association of parents' marital status but the significant association of the number of close friend with the clustering of risk behaviours provided some evidence supporting the theories of human development, which stipulated that adolescents are more influenced by their peers than by their parents because they have more common characteristics with their peers [52]. Another plausible reason for this nonsignificant association is that other important familyrelated determinants such as family cohesion [53] and parental conventionality [54] were not investigated in the present study and therefore should be explored in future studies.

The present study had a few limitations. First, the crosssectional nature of the study precluded causal claims on the sequence of engagement in the five lifestyle risk behaviours. Second, the inclusion of school-going adolescents aged 16-17 years limited the generalisation of the present findings to adolescents of other age groups and those not enrolled in upper secondary school (the enrolment rate of upper secondary school was $84.75 \%$ in 2013) [55]. Third, the self-reported responses for all five risk behaviours might have given rise to under-reporting due to social desirability bias, especially for alcohol use. Fourth, the use of a binary outcome variable in the multivariable logistic regression could have limited the interpretation of the associations between sociodemographic factors and clustering of lifestyle risk behaviours. However, there were a few reasons for the dichotomisation of the outcome variable. First, we aimed to identify the sociodemographic determinants of those who were more likely to have clustered lifestyle risk behaviours, as compared to their counterparts who did not have clustered lifestyle risk behaviours, regardless of the type of combination, because there are too many combinations (32 combinations) to be scrutinised individually. Second, some combinations had fewer respondents (less than 20), and given the number of predictors in the regression model, dichotomising the 
outcome variable would be a better option for a valid and reliable results. Third, underscoring the efficiency of cluster analysis, we had run a two-step cluster analysis, and a total of 7 discernible clusters were deduced. A multinomial logistic regression of this 7-level outcome variable with the same set of predictors as the binary regression model was performed, however, we found that there were a total of 1028 (69.3\%) cells (i.e. cluster levels by predictors) with zero frequencies and therefore made findings from the multinomial regression less reliable. Nonetheless, despite the limitations, the present study is of particular relevance and importance, as it is the first study to provide a holistic illustration of different combinations of clustered lifestyle risk behaviours and the magnitude of clustering rather than individual behaviours among school-going Malaysian adolescents.

\section{Conclusion}

The present study clearly demonstrated the clustering of a number of specific combinations of lifestyle risk behaviours among Malaysian adolescents. Early intervention programmes that target the high-risk groups identified in the present study are greatly needed to reduce the increasing burden of non-communicable diseases in Malaysia, which are commonly attributable to the five major modifiable lifestyle risk behaviours studied.

\section{Abbreviations}

aOR: Adjusted odds ratio; BMl: Body mass index; Cl: Confidence interval; E: Expected prevalence; GSHS: Global School Health Survey; MREC: Medical Review and Ethics Committee; MyAHRB: Malaysian Adolescent Health Risk Behaviour; O: Observed prevalence; O/E: Observed prevalence-to-expected prevalence

\section{Acknowledgements}

We would like to thank the Director-General of Health, Malaysia for his permission to publish this paper. We would also like to acknowledge the honorary involvement of the students at the Allied Health College as data collectors.

\section{Authors' contributions}

$\mathrm{TCH}$, as the first author, analysed and interpreted the data and drafted the manuscript. TMW, SMG and HPP helped in the literature review, prepared the results and discussion sections of the article and helped to draft the manuscript. LKH and KCC conceptualised and designed the study as well as critically reviewed the manuscript. MZTH, CYY and NHMI assisted in the data analysis and interpretations. TEO collected data, supervised the data collection in the field and critically revised the manuscript. FK reviewed and revised the manuscript for important intellectual content. All authors gave their final approval to publish the submitted manuscript in its present form.

\section{Funding}

No funding was received for the MyAHRB study.

\section{Availability of data and materials}

The datasets for the MyAHRB study are not publicly available due to government policies. Data are, however, available from the corresponding author (Teh $\mathrm{CH}$ ) upon reasonable request and with the permission of the Director-General of Health, Malaysia.

\section{Ethics approval and consent to participate}

The MyAHRB study was approved by the Medical Research and Ethics Committee (MREC), Ministry of Health Malaysia (NMRR-12-1210-12399) and the State Education Department, Ministry of Education, Malaysia, granted permission to conduct this study. Passive consent was obtained from the parents/guardians of all selected students as per the MREC Guidelines on Health Research Involving Minors.

\section{Consent for publication}

The parents/guardians of the selected students understood that the collected data would be used for research purposes only, which also includes the publication of anonymous data as explained in the informed consent form

\section{Competing interests}

There were no conflicts of interest among the authors.

\section{Author details}

${ }^{1}$ Institute for Medical Research, Ministry of Health, Jalan Setia Murni U13/52, 40170 Seksyen U13, Bandar Setia Alam, Malaysia. ${ }^{2}$ Hospital Tengku Ampuan Rahimah, Jalan Langat, 41200 Klang, Selangor, Malaysia. ${ }^{3}$ Institute for Public Health, Ministry of Health, Jalan Bangsar, 50590 Kuala Lumpur, Malaysia.

${ }^{4}$ Allied Health Science College, Jalan Hospital, 47000 Sungai Buloh, Selangor, Malaysia.

Received: 3 January 2019 Accepted: 19 August 2019

Published online: 27 August 2019

\section{References}

1. Steinberg L. Cognitive and affective development in adolescence. Trends Cogn Sci. 2005;9(2):69-74.

2. Leech RM, McNaughton SA, Timperio A. The clustering of diet, physical activity and sedentary behaviour in children and adolescents; a review. 2014;11(4). https://doi.org/10.1186/1479-5868-11-4.

3. MeaderN KK, Moe-Byrne WK, Graham H, Petticrew M, et al. A systematic review on the clustering and co-occurrence of multiple risk behaviours. BMC Public Health. 2016;16(657). https://doi.org/10.1186/s12889-016-3373-6.

4. Ness AR, Maynard M, Frankel S, Smith GD, Frobisher C, Leary SD, et al. Diet in childhood and adult cardiovascular and all cause mortality: the Boyd Orr cohort. Heart. 2005;91:894-8.

5. World Health Organisation. The global burden of disease: 2004 update. Geneva: WHO Press; 2008.

6. Urrutia-Pereira M, Oliano VJ, Aranda CS, Mallol J, Sole D. Prevalence and factors associated with smoking among adolescents. J Pediatr 2017; 93(3). doi: https://doi.org/10.1016/j.jped.2016.07.003.

7. Lim KH, Lim HL, Teh CH, Kee CC, Khoo YY, Shubash SG, et al. Smoking among school-going adolescents in selected secondary schools in Peninsular Malaysia- findings from the Malaysian Adolescent Health Risk Behaviour (MyAHRB) study. Toblnduc Dis. 2017;15(9). https://doi.org/10.11 86/s12971-016-0108-5.

8. Jorge KO, Ferreira RC, Ferrerira EF, Vale MP, Kawachi I, Zarzar PM. Binge drinking and associated factors among adolescents in a city in southeastern Brazil: a longitudinal study. Cad Saúde Pública. 2017;33(2). https://doi.org/1 0.1590/0102-311x00183115.

9. Manickam MA, Abdul Mutalip MH, Abdul Hamid HA, Kamaruddin RB, Sabtu MY. Prevalence, comorbidities, and cofactors associated with alcohol consumption among school-going adolescents in Malaysia. Asia Pac J Public Health. 2014;26(5):91S-9S.

10. Oyeyemi A, Ishaku CM, Oyekola J, Wakawa HD, lawan A, Yakubu S, et al. Patterns and associated factors of physical activity among adolescents in Nigeria. PLoS One. 2016;11(2). https://doi.org/10.1371/journal.pone.0150142.

11. Baharudin A, Zainuddin AA, Manickam MA. AmbakRashidah, Ahmad MH, Naidu BM, et al. factors associated with physical inactivity among schoolgoing adolescents. Asia Pac J Public Health. 2014;26(5):27S-35S. https://doi. org/10.1177/1010539514543682.

12. Nascente FM, Jardim TV, Peixoto MD, Carneiro CS, Mendonca KL, Povoa TI, et al. Sedentary lifestyle and its associated factors among adolescents from public and private schools of a Brazilian state capital. BMC Public Health. 2016;16(1). https://doi.org/10.1186/s12889-016-3836-9.

13. Peltzer K, Pengpid S. Leisure Time Physical Inactivity and Sedentary Behaviour and Lifestyle Correlates among Students Aged 13-15 in the Association of Southeast Asian Nations (ASEAN) Member States, 2007-2013. Int J Environ Res Public Health. 2016;13(217). https://doi.org/10.3390/ ijerph13020217. 
14. Sa D-O, Buchner DM, Andrade JE, Grigsby-Toussaint DS. A comparative study of fruit and vegetable consumption and physical activity among adolescents in 49 low-and-middle-income countries. Sci Rep. 2018;8. https:// doi.org/10.1038/s41598-018-19956-0.

15. Rezali FW, Chin YS, Shariff ZM, MohdYusoff BN, Sanker K, Woon FC. Evaluation of diet quality and its associated factors among adolescents in Kuala Lumpur. Malaysia Nutr Res Pract. 2015;9(5):511-6. https://doi.org/1 0.4162/nrp.2015.9.5.511.

16. Schuit AJ, van Loon AJM, Tijhuis M, Ocke MC. Clustering of lifestyle risk factors in a general adult population. Prev Med. 2002;35:219-24.

17. Breslow L, Enstrom JE. Persistence of health habits and their relationship to mortality. Prev Med. 1980;9:469-83.

18. Ebrahim S, Montaner D, Lawlor DA. Clustering of risk factors and social class in childhood and adulthood in British women's heart and health study: cross-sectional analysis. Br Med J. 2004. https://doi.org/10.1136/bmj.38034. 702836.55.

19. Doll R, Peto R. The causes of cancer: quantitative estimates of avoidable risks of cancer in the United States today. J Natl Cancer Inst. 1981;6:1191-308.

20. Schlecht NF, Franco EL, Pintos J, Negassa A, Kowalski LP, Oliveira BV, et al. Interaction between tobacco and alcohol consumption and the risk of cancers of the upper aero-digestive tract in Brazil. Am J Epidemiol. 1999;150:1129-37.

21. Jessor R. Risk behaviour in adolescence: a psychosocial framework for understanding and action. J Adolesc Health. 1991;12:597-605.

22. McAloney K, Graham H, Law C, Platt L. A scoping review of statistical approaches to the analysis of multiple health-related behaviours. Prev Med. 2013;56:365-71

23. Sanchez A, Norman GJ, Sallis JF, Calfas KJ, Cella J, Patrick K. Patterns and correlates of physical activity and nutrition behaviors in adolescents. Am J Prev Med. 2007:32:124-30.

24. Dumith SC, Muniz L, Tassitano RM, Hallal PC, Menezes AMB. Clustering of risk factors for chronic diseases among adolescents from southern Brazil. Prev Med. 2012:54:393-6.

25. Poortinga $W$. The prevalence and clustering of four major lifestyle risk factors in an English population. Prev Med. 2007;44:124-8.

26. da Costa FF, Benedet J, Leal DB, Assis MAA. Clustering of risk factors for non communicable diseases in adults from Florianopolis. SC Rev Bras Epidemiol. 2013;16(2):398-408.

27. Centers of Disease Control and Prevention: Global School Health Survey (GSHS) Questionnaire. http://www.cdc.gov/gshs/questionnaire/. Accessed 29 Dec 2015

28. Centers of Disease control and Prevention: Youth Behavior Risk Surveillance. http://ftp.cdc.gov/pub/data/yrbs/2013/2013 xxh_questionnaire.pdf. Accessed 29 Dec 2015

29. World Health Organisation. Global Recommendations on Physical Activity for Health. Geneva: WHO Press; 2010.

30. World Health Organisation: Global School-based Student Health Survey Malaysia 2012 Fact Sheet. https://www.who.int/ncds/surveillance/gshs/ Malaysia_2012_GSHS_FS_national.pdf. Accessed 16 Dec 2018.

31. Ministry of Health Malaysia. Malaysian Dietary Guidelines. Putrajaya: WHO Press; 2010.

32. World Health Organisation. Preventing chronic diseases a vital investment Geneva: WHO Press; 2005. http://www.who.int/chp/chronic_disease_report/ full_report.pdf?ua=1. Accessed 13 Nov 2018. (ISBN No. 92-4-156300-1)

33. Lawlor DA, O'Callaghan MJ, Mamun AA, Williams GM, Bor W, Najman JM. Socioeconomic position, cognitive function, and clustering of cardiovascular risk factors in adolescence: findings from the Mater University study of pregnancy and its outcomes. Psychosom Med. 2005;67:862-8.

34. Alamian A, Paradis G. Clustering of chronic disease behavioural risk factors in Canadian children and adolescents. Prev Med. 2009;48:493-9.

35. Tyas S, Pederson L. Psychosocial factors related to adolescent smoking: a critical review of the literature. Tob Control. 1998;7(4):409-20.

36. World Health Organisation. Alcohol, gender and drinking problems: perspectives from low and middle income countries. Geneva: WHO Press; 2005.

37. Wee LH, Caryn CMH, Nantha YS, MRCGP. A review of smoking research in Malaysia. Med J Malaysia. 2016;71(1):29-41.

38. Muniz LC, Schneider BC, Silva IC, Matijasevich A, Santos IS. Accumulated behavioural risk factors for cardiovascular diseases inSouthern Brazil. Rev Saude Publica. 2012;46(3):534-42.
39. Chiolero A, Wietlisbach V, Ruffieux C, Paccaud F, Cornuz J. Clustering of risk behaviors with cigarette consumption: a population-based survey. Prev Med. 2006:42:348-53.

40. Klein-Geltink JE, Choi BC, Fry RN. Multiple exposures to smoking, alcohol, physical inactivity and overweight: prevalences according to the Canadian community health survey cycle 1.1. Chronic Dis Can. 2006;27:25-33.

41. Ha S, Choi HR, Lee YH. Clustering of four major lifestyle risk factors among Korean adults with metabolic syndrome. PLoS One. 2017;12(3):e0174567. https://doi.org/10.1371/journal.pone.0174567.

42. Jensen MK, Sorensen TI, Andersen AT, Thorsen T, Tolstrup JS, Godtfredsen NS, et al. A prospective study of the association between smoking and later alcohol drinking in the general population. Addiction. 2003;98(3):355-63 Epub 2003/02/27.

43. Atkins D, Clancy C. Multiple risk factors interventions. Are we up to the challenge? Am J Prev Med. 2004;27(2):102-3.

44. Elliott MR, Shope JT, Raghunathan TE, Waller PF. Gender differences among young drivers in the association between high-risk driving and substance use/ environmental influences. J Stud Alcohol. 2006;67(2):252-60.

45. Nolen-Hoeksema S. Sex differences in unipolar depression: evidence and theory. Psychol Bull. 1987;101:259-82.

46. Nolen-Hoeksema S, Girgus JS. The emergence of gender differences in depression during adolescence. Psychol Bull. 1994;115:424-43.

47. Dumont M, Provost MA. Resilience in adolescents: protective role of social support, coping strategies, self-esteem, and social activities on experience of stress and depression. J Youth Adolesc. 1999;28(3):343-63 doi: 0047-2891/ 99/0600-0343.

48. Hirschi T. Causes of delinquency. Berkeley: University of California Press; 1969

49. Suliman H. Alcohol and Islamic faith. Drug Alcohol Depend. 1988;11:63-5.

50. Blum RW, McNeely CA, Rinehart PM. Improving the odds: the untapped power of schools to improve the health of teens. Center for Adolescent Health and Development. Minneapolis: University of Minnesota; 2002.

51. Centers for Disease Control and Prevention. School Connectedness: Strategies for Increasing Protective Factors Among Youth. Atlanta: Department of Health and Human Services; 2009.

52. Santrock JW. Adolescence. 11th ed. Boston: McGraw-Hill; 2005.

53. Rattay $P$, von der Lippe E, Mauz E, Richter F, Holling H, Lange C, Lampert T. Health and health risk behaviours of adolescents - differences according to family structure. Results of the German KiGGS cohort study. PLoS One. 2018; 13(3):e0192968. https://doi.org/10.1371/journal.pone.0192968.

54. Brooks FM, Magnusson J, Spencer N, Morgan A. Adolescent multiple risk behavior: an asset approach to the role of family, school and community. J Pub Health. 2012;34(1):i48-6. https://doi.org/10.1093/pubmed/fds001.

55. Ministry of Education. Malaysia Educational Statistics 2016. Malaysia; 2016. ISSN 1985-6407. https://www.moe.gov.my/images/Terbitan/Buku-informasi/ QUICK-FACTS-2016/QUICK\%20FACTS\%202016.pdf. Accessed 3 Jan 2019

\section{Publisher's Note}

Springer Nature remains neutral with regard to jurisdictional claims in published maps and institutional affiliations.

Ready to submit your research? Choose BMC and benefit from:

- fast, convenient online submission

- thorough peer review by experienced researchers in your field

- rapid publication on acceptance

- support for research data, including large and complex data types

- gold Open Access which fosters wider collaboration and increased citations

- maximum visibility for your research: over $100 \mathrm{M}$ website views per year

At $\mathrm{BMC}$, research is always in progress.

Learn more biomedcentral.com/submission 